\title{
Multiple cranial nerve palsies in a case of intracranial plasmacytoma and multiple myeloma: A report
}

\author{
Bishwamit Bhattacharya $^{1}$, Bitoti Chattopadhyay ${ }^{2}$, Atri Chatterjee ${ }^{3}$, Anup K Boler ${ }^{4}$, \\ Nirod B Debnath ${ }^{5}$
}

1. Department of Radiotherapy, Calcutta Medical College, Kolkata, India. 2. Department of Medicine, Nil Ratan Sircar Medical College, Kolkata, India. 3. Department of Medicine, Nil Ratan Sircar Medical College, Kolkata, India. 4. Department of Pathology, Nil Ratan Sircar Medical College, Kolkata, India. 5. Department of Medicine, Nil Ratan Sircar Medical College, Kolkata, India.

Correspondence: Chatterjee Atri. Address: Department of Medicine, Nil Ratan Sircar Medical College, 138, A.J.C. Bose Road, Kolkata- 700014, India. Email: chatterjee.atri@gmail.com

Received: May 24, 2013

DOI : $10.5430 /$ jst.v4n1p38
Accepted: September 23, 2013

URL: http://dx.doi.org/10.5430/jst.v4n1p38

\section{Abstract}

Multiple myeloma is usually associated with neurological features like peripheral neuropathy and compressive myelopathy. It is unusual for multiple myeloma to present with multiple cranial nerve palsies. We report a case of multiple myeloma with an extramedullary plasmacytoma in the maxillary antrum, which resulted in multiple cranial nerve palsies. The patient was diagnosed to have IgG $\lambda$ subtype in stage II according to the international staging system (ISS). The patient did not respond to a combination of radiotherapy and chemotherapy.

\section{Key words}

Extramedullary plasmacytoma, Cranial nerve palsy, Maxillary sinus

\section{I ntroduction}

Neurological symptoms in multiple myeloma include hyperviscosity, hypercalcemia, spinal cord compression and amyloid or drug-related neuropathy ${ }^{[1]}$. One of the most common neurological complications is spinal cord compression for epidural plasmacytomaor vertebral fracture. Peripheral neuropathy on account of the antibodies directed against myelin structures or on account of amyloid deposits is often present in patients that have multiple myeloma. We report the case of a 30 year old patient who presented with multiple cranial nerve palsies and was subsequently diagnosed to have multiple myeloma with an intracranial plasmacytoma.

\section{Case report}

A 30 year old female patient presented with progressively worsening, dull headache of six weeks duration and she developed diplopia, right sided ptosis and facial weakness over the last two weeks. She also had two recent episodes of epistaxis. She denies any complaint of vomiting, convulsion, altered sensorium, dysphagia, hoarseness of voice, nasal regurgitation, hearing loss, tinnitus, vertigo, and fever or bone pain. On examination, she had right 3 rd cranial nerve palsy along with lower motor neuron palsy of the right 7 th and left 12 th cranial nerves. There were two hard, fixed, non-tender 
bony swellings over the right infra-orbital region and the right shoulder. Examination of other systems was noncontributory.

Initial laboratory investigations showed normocytic normochromic anaemia with increased rouleaux formation $(\mathrm{Hb}$ : 8.9g/dL, MCV: 94.9fl), normal WBC and platelet count (TLC: $8,300 / \mathrm{mm}^{3}$; Platelet count: $180,000 / \mathrm{mm}^{3}$ ) and high erythrocyte sedimentation rate $(136 \mathrm{~mm}$ in first hour). Other routine tests revealed Bence-Jones proteinuria, hypergammaglobulinemia (Total protein:10.5g/dL, albumin:3.2g/dL, globulin:7.3g/dL), normal serum calcium (10.4mg/ $\mathrm{dL}$ ) and elevated serum lactate dehydrogenase (782 U/L). Serum protein electrophoresis showed presence of M-band in the $\gamma$-globulin region $(3.4 \mathrm{~g} / \mathrm{dL})$. The monoclonal protein was typed as IgG lambda light chain on immunofixation in both blood and urine. A bone marrow aspirate showed $26 \%$ plasma cells with immature and bi-nucleate forms and occasional sheets and clustering (Figure 1). Immunohistochemistry of bone marrow biopsy revealed the plasma cells to be CD38+, CD138+, CD56+, CD19- which is typical of neoplastic plasma cells. Serum $\beta 2$-microglobulin was elevated (4400mcg/L, Reference range: $800-2200 \mathrm{mcg} / \mathrm{L}$ ). HIV serology was negative.

Figure 1. Bone marrow aspirate showed sheets of plasma cells with rouleaux formation, 400X, Leishman stain

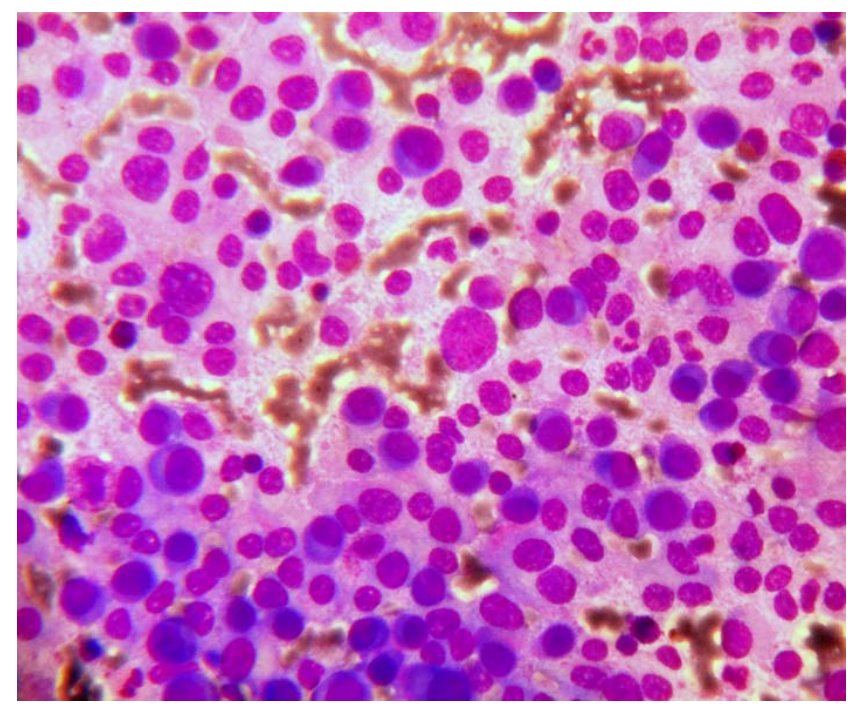

Contrast enhanced CT scan of paranasal sinuses showed an increased attenuating soft tissue lesion in the right maxillary antrum eroding into the right orbit with intracranial epidural extension into the right temporal area (Figure 2). Nasal endoscopy-guided biopsy from the antral mass revealed extra medullary plasmacytoma. Skeletal survey showed an osteolytic mass lesion involving the lateral end of right clavicle which alsorevealeda plasmacytoma on fine needle aspiration cytology (Figure 3). There was no other osteolytic lesion elsewhere.

The patient was diagnosed to have multiple myeloma of IgG- $\lambda$ sub-type; ISS stage II, with symptomatic intracranial plasmacytoma. So, the patient was started on whole brain external beam radiotherapy and 30 Gy was delivered in 10 fractions over 2 weeks ( $3 \mathrm{~Gy} /$ fraction, single fraction per day, 5 days per week). Patient was relieved of distressing headache following whole brain radiotherapy. Thereafter, the patient was started on systemic chemotherapy with VAD protocol [Vincristine $0.5 \mathrm{mg} / \mathrm{m}^{2} /$ day on days $1-4$, Doxorubicin $9 \mathrm{mg} / \mathrm{m}^{2} /$ day on days $1-4$, Dexamethasone 40mg days 1-4, 9-12, 17-20, repeated every 28 days]. The induction regimen was chosen keeping in mind patient's young age, possibility of autologous stem cell transplantation in future and her financial constraints which barred us from using bortezomib and thalidomide. During the second cycle of induction chemotherapy, she got admitted with fever, diarrhoea and extensive muco-cutaneous candidiasis. Despite prompt institution of fluid resuscitation, appropriate broad spectrum antibiotics and antifungals, she succumbed to septic shock two days later. 
Figure 2. CT of the paranasal sinuses showed a soft tissue mass (arrowhead) in the right maxillary antrum eroding into the right orbit and nasal cavity

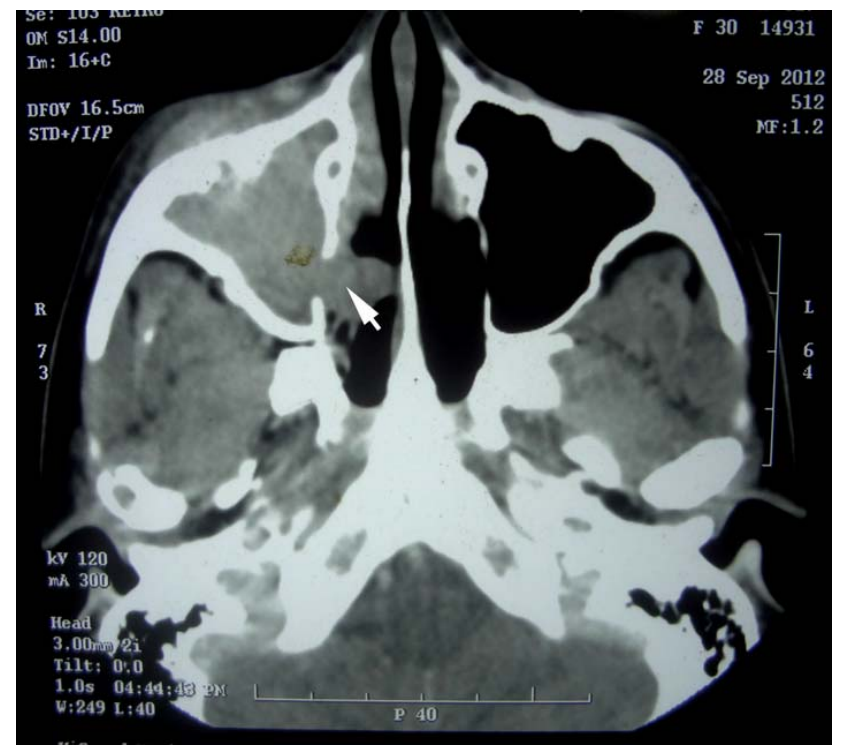

Figure 3. Fine needle aspiration cytology from the osteolytic lesion of right clavicle showed numerous plasma cells (arrowheads) and lymphocytes, 400X, MGG stain

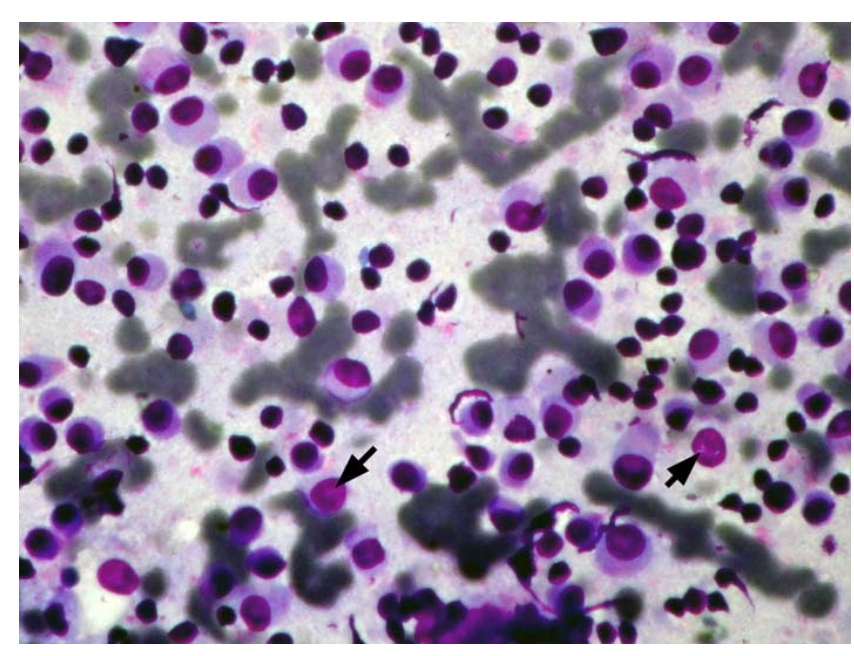

\section{Discussion}

Neurologic symptoms due to plasmacytoma located either in an intracranial location or in the base of the skull are extremely rare. Two series dealt with eight and nine patients respectively, with intracranial plasmacytomas that underwent surgical management ${ }^{[1,2]}$ and the rest were case reports ${ }^{[3-9]}$. Few cases have been reported that included almost all cranial nerves (III to XII), and different syndromes that involved different cranial nerve groups, for example, Collet-Sicard syndrome affects the IX, X, XI, and XII cranial nerves ${ }^{[6]}$, lateral-wall cavernous sinus involvement affects the V and VI cranial nerves (also III and IV at times) ${ }^{[7]}$. Our patient had involvement of III and VII cranial nerve on right side and XII on left side. The neuropathy is caused by the direct compression of nerves either in their intracranial course, especially when there is involved with the body of the sphenoid or the apex of the petrous bone, or at the cranial outlets in the base of the skull. Imaging showed destructive masses involving osseous structures (sella turcica, clival bone, petrousbone, occipital foramen). Plasmacytomas at the base of the skull generally develop in the background of pre-existing multiple myeloma. If it isn't already present, myeloma is likely to develop in a rapid manner ${ }^{[1,2]}$.

The present patient is notably younger than the average age of presentation of multiple myeloma. In India the median age of patients presenting with myeloma is 55 years, a decade earlier than that in the USA ${ }^{[10]}$. In a retrospective analysis of 534 patients in New Delhi by Kumar et al, $11.4 \%$ of the patients were less than 40 years of age ${ }^{[11]}$. 
In conclusion, we report a case of multiple myeloma in a young female having extramedullary plasmacytoma involving right maxillary antrum, orbit, base of skull with intracranial epidural extension presenting with multiple cranial nerve palsies. Though rare, multiple myeloma should be considered in differential diagnosis of such patients.

\section{References}

[1] Bindal AK, Bindal RK, van Loveren H, et al. Management of intracranialplasmacytoma. J Neurosurg. 1995; 83: $218-221$. PMid:7616264 http://dx.doi.org/10.3171/jns.1995.83.2.0218

[2] Schwartz TH, Rhiew R, Isaacson SR, et al. Association betweenintracranial plasmacytoma and multiple myeloma: Clinicopathological outcomestudy. Neurosurgery. 2001; 49: 1039-1045. PMid:11846895

[3] Giraldo MP, Sa'nchez Jacob M, Rubio Félix D, et al. Myeloma withouta monoclonal component with tumor and neurologic manifestations. Sangre(Barc). 1987; 32: 517-518.

[4] Delgado Lamas JL, Vazquez Villegas V, Galvan Villegas F. Multiplemyeloma and destruction of the sella turcica. Sangre (Barc). 1990; 35: 237-238.

[5] Forrett-Kaminsky MC, Scherer C, Platini C, et al. Isolated paralysis ofthe great hypoglossal nerve disclosing multiple myeloma. Rev Neurol (Paris). 1991; 147: 238-239.

[6] Tappin JA, Satchi G, Corless JA, et al: Multiple myeloma presenting asthe Collet-Sicard syndrome. J NeurolNeurosurg Psychiatry. 1996; 60: 14. PMid:8558142 http://dx.doi.org/10.1136/jnnp.60.1.14

[7] Cockerell OC, Kapoor R: Cranial neuropathy. Postgrad Med J. 1997; 73: 441-442. PMid:9338038 http://dx.doi.org/10.1136/pgmj.73.861.441

[8] Weihrauch MR, Diehi V. Retrobulbar, intracranial, and cutaneous secondary plasmacytomas in a patient with atypical multiple myeloma. N Engl J Med. 2001; 345: 1917. PMid:11756588 http://dx.doi.org/10.1056/NEJM200112273452614

[9] Joshi A, Jiang D, Singh P. Skull base presentation of multiple myeloma. Ear Nose Throat J. 2011; 90: E6-9. PMid:21229500

[10] National Cancer Registry Programme. Two year report of the Population based Cancer registries 1999-2000. New Delhi: Indian Council of Medical Research. 2005.

[11] Kumar L, Vikram P, Kochupillai V. Recent advances in the management of multiple myeloma:Natl Med J India. 2006; 19: 80-9. PMid:16756196 